Published in final edited form as:

Cancer Biomark. 2011 ; 9(1-6): 461-473. doi:10.3233/CBM-2011-0176.

\title{
Renal Cell Carcinoma
}

\author{
Paul Cairns, PhD \\ Departments of Surgical Oncology and Pathology, Fox Chase Cancer Center, Philadelphia, PA \\ 19111, Tel: 215728 5635, Fax: 2157282741
}

Paul Cairns: p_cairns@fccc.edu

\section{Abstract}

Renal Cell Carcinoma (RCC) has the highest mortality rate of the genitourinary cancers and the incidence of RCC has risen steadily. If detected early, RCC is curable by surgery although a minority are at risk of recurrence. Increasing incidental detection and an ageing population has led to active surveillance as an option for patients with small renal masses. RCC is heterogeneous and comprises several histological cell types with different genetics, biology and behavior. The identification of the genes predisposing to inherited syndromes with RCC has provided much of our knowledge of the molecular basis of early sporadic RCC. Many of the oncogenes and tumor suppressor genes that are mutated leading to pathway dysregulation in RCC remain to be elucidated. Global studies of copy number, gene sequencing, gene expression, miRNA expression and gene methylation in primary RCC will lead towards this goal. The natural history of RCC indicated by candidate precursor lesions, multifocal or bilateral disease, growth rate of small renal masses under surveillance, and high risk populations provide insight into the behavior of this disease. The use of molecular markers for early detection and prognosis merits more attention with ongoing advances in omics technologies. This review focuses on early RCC, that is disease confined within the renal capsule.

\section{Keywords}

RCC; Genetics; Epigenetics; Natural history

\section{Incidence, Risk Factors and Clinical Features}

In recent decades, the incidence of RCC has been steadily rising by $2-4 \%$ each year and RCC is now the 7th leading cancer type in men in the US. In 2010, it is projected that in the US there will be approximately 58,000 new cases of, and 13,000 deaths from, kidney cancer, the vast majority being RCC [1]. Compared to 1971, there has been a 5-fold increase in the incidence of, and a two-fold increase in mortality from, RCC [2]. Increasing use of imaging for other medical indications has resulted in more RCCs found by incidental detection but this does not entirely explain the rise in incidence. The gender ratio is approximately male 2:1 female. African Americans have both a higher incidence and mortality rates for kidney cancer [3]. Cigarette smoking, obesity, hypertension and/or related medications have been implicated as risk factors although the increase in risk is relatively modest [4]. The etiology of most RCCs remain unclear. Approximately $2-4 \%$ of RCC is hereditary and since the predisposition genes have been identified, genetic screening can identify carriers who represent a group at high risk of RCC. Another population at high risk for RCC is individuals at an advanced stage of chronic kidney disease (CKD) on long-term dialysis. More than 100,000 people will begin treatment for end stage renal disease (ESRD) this year (www.cdc.gov) among the almost 20 million with CKD in the US. 
Early clinical manifestations of RCC are diverse and may give rise to a range of non-specific and often misattributed symptoms. Only $10 \%$ of individuals with RCC present with the classic triad of hematuria, pain and a flank mass and these individuals most often have advanced disease. More than $40 \%$ of individuals with RCC present with none of these three symptoms [5]. Currently, more than $60 \%$ of RCC are detected incidentally in patients not suspected of harboring a genitourinary malignancy. While this has led to stage migration, it has not at all diminished the number of individuals that present with metastatic disease. RCC has the highest mortality rate of the genitourinary cancers, as more than a third of patients with RCC will die from disease. At presentation, a third of patients with RCC already have locally advanced or metastatic disease and a third of patients who undergo surgical resection for local disease will have a recurrence. Patients with metastatic RCC (pT4) have a median survival of around 13 months and the 5 year survival rate is under 10\% [6]. Early stage (pT1-2) RCC confined to the kidney can be cured by surgery. Traditionally this was radical nephrectomy but nephron sparing surgery is becoming more widely used for localized disease reducing risk of cardiac disease and premature death due to late renal insufficiency. Presently, diagnosis of RCC is confounded by the lack of a cancer-specific diagnostic technique [6]. Novel and well conceived approaches for the detection and management of renal cancer are therefore extremely important. Active surveillance with delayed primary treatment has been proposed as a management option for selected patients with RCC to defer, and possibly avoid, the negative consequences of surgery

In the US, more than 200,000 people are thought to be living with kidney cancer. More than $10 \%$ of individuals with organ-confined (pT1 and T2) RCC progress usually within 3-5 years. Clinical trials of sunitinib or sorafenib as adjuvant therapy for RCC patients at high risk of recurrence RCC i.e. high grade pT1b and any grade pT2, are ongoing. However, at present, there is no adjuvant therapy for organ-confined RCC, only observation. Similarly, patients with locally advanced disease (pT3) have disparate characteristics that affect therapeutic outcomes. Better predictors of behavior and response are needed to more appropriately guide treatment of the individual patient and to predict prognosis [7]. Until recently, there were few therapeutic options other than the cytokines interferon or interleukin-2 for RCC. Two small molecule kinase inhibitors, sunitinib and sorafenib, are becoming standard of care for metastatic RCC as studies support improvements in progression-free and overall survival. The mammalian target of rapamycin (mTOR) inhibitors, temsirolimus and everolimus, as well as the monoclonal antibody, bevacizumab, and the angiogenesis inhibitor, pazopanib, are also in clinical trials [8].

\section{Overview of Origin, Cell Type, Stage and Grade}

Human RCCs are thought to arise from a variety of specialized cells located along the length of the nephron. RCC is comprised of several histological cell types. Both clear cell and papillary RCC are thought to arise from the epithelium of the proximal tubule.

Chromophobe RCC, oncocytoma, and collecting duct RCC are believed to arise from the distal nephron, probably from the epithelium of the collecting tubule. Each type has differences in genetics, biology and behavior. The most common histological type is clear cell carcinoma, also called conventional RCC, which represents 75-80\% of RCC. Papillary $(10-15 \%)$, chromophobe (5\%) and other more rare forms such as collecting duct carcinoma $(<1 \%)$ comprise the remainder. Oncocytomas represent 3-7\% of renal masses but are invariably benign and their exclusion from classification as RCC has been recommended [9]. Distinct tumors of different cell types can occasionally be seen in the same kidney. An individual tumor can have mixed histologies. The pathologist differentiates cell types routinely by morphology and immunohistochemical markers as well as by cytogenetic and molecular genetic analysis particularly when the cell type is equivocal. Three to five per cent of RCC cannot be classified and are termed RCC, unclassified. Sarcomatoid RCC is no 
longer considered as a true subtype since sarcomatoid change represents undifferentiated cells associated with progression of disease in all RCC cell types [9].

Pathologic stage, based on the size of the tumor and the extent of invasion, is the most important prognostic indicator. The TNM staging system defines local extension of the primary tumor $(\mathrm{T})$, involvement of regional lymph nodes $(\mathrm{N})$, and presence of distant metastases (M) and stage of RCC follows TNM classification. In the 2010 AJCC Cancer Staging guidelines, T1a RCC are $4 \mathrm{~cm}$ or less, T1b are more than 4 but not more than $7 \mathrm{~cm}$, T2a tumors are larger than $7 \mathrm{~cm}$ but less or equal to $10 \mathrm{~cm}, \mathrm{~T} 2 \mathrm{~b}$ are more than $10 \mathrm{~cm}$ in size but confined within the kidney. T1 and T2 are equivalent to stage I and stage II [10]. T3 and T4 RCC have invaded outside the kidney and are not considered as "early" RCC for this review. DeCastro and McKiernan review the revisions in the TNM system over time in regard to size of RCC and stage [3]. An analysis of the incidence of RCC in the US from 1986-1998 based on SEER data reported stage at presentation to be 54\% localized (stage I or II), 21\% regional (stage III), 25\% advanced (stage IV) [11].

Chromophobe RCC appears to have a better survival than clear cell RCC. Localized papillary RCC shows a more favorable outcome than localized clear cell RCC but there is no apparent difference in 5 year survival for extra renal papillary compared to extra renal clear cell RCC [12]. Virtually all metastatic RCC are clear cell. Fuhrman grades of I-IV have been shown to correlate with outcome in clear cell RCC but the utility of grade is less agreed on for other histologic types. Low grade and high grade are used as one of the criteria to separate papillary RCC into types I and II. The vast majority of chromophobe RCC are low grade while oncocytomas are not graded. Within an individual stage, grade has prognostic value for clear cell RCC [13].

\section{Molecular Basis of Clear Cell RCC}

Clear cell RCC can be sporadic ( $>96 \%)$ or familial $(<4 \%)$ [14]. Almost all familial clear cell RCC arise from an inherited mutation in the von Hippel-Lindau (VHL) tumor suppressor gene located on chromosome 3p [15]. Patients with VHL syndrome show kidney cysts and multiple bilateral clear cell RCC at an average 37 years of age [16]. The second allele of VHL has been shown to be inactivated by deletion and less commonly by promoter hypermethylation or rearrangement in the RCC. The average age of onset of sporadic clear cell RCC is 61 years and it usually presents as a solitary tumor of several centimeters in size [16]. Chromosome 3p deletion and inactivation of the VHL suppressor gene is the most common genetic alteration [17]. The facts that VHL inactivation is so common in sporadic clear cell RCC including the smallest T1a tumors, that this is also the predisposing factor in familial predisposition, and that where RCCs show only one chromosomal loss it is invariably $3 p$, argue that alteration of VHL is the initiating event in most sporadic clear cell RCC. Inactivation of VHL is specific to clear cell RCC and is not found in other histological cell types of RCC. Approximately, two-thirds of sporadic clear cell RCC have definite evidence for biallelic inactivation of VHL, based on 55\% of a series of 104 tumors showing point mutation by sequence analysis [18] and an estimated further 10-15\% having promoter hypermethylation [19] associated with transcriptional inactivation. Loss of heterozygosity (LOH) of 3p including the VHL gene locus was seen in 87\% of clear cell RCC [18]; homozygous deletion and rearrangment may account for further cases of biallelic inactivation. It remains unclear if there is a subset of clear cell RCC with functional VHL or that this is due to the limitations of mutation analysis or other mechanisms of inactivation of VHL will be uncovered. Based on mRNA signatures and immunohistochemical analysis within VHL-deficient sporadic clear cell RCC, a subtype distinguished by overexpression of both HIF1 $\alpha$ and HIF2 $\alpha$ called H1H2 tumors and another subtype defined by expression of HIF $2 \alpha$ only called H2 tumors have been found [20]. The protein encoded by the VHL gene 
is a component of the elongin complex and is involved in the ubiquitination and degradation of hypoxia-inducible-factor (HIF), which is a transcription factor that plays a central role in the regulation of gene expression by oxygen. Inactivation of the VHL gene in clear cell tumors leads to activation of the hypoxia pathway via hypoxia-inducible factor- $1 \alpha$ (HIF1A) and hypoxia-inducible factor- $2 \alpha$, which in turn activates expression of genes involved in the hypoxia response, angiogenesis, and other signaling pathways involving vascular endothelial growth factor (VEGF) [21]. This work provided a rationale for the use of VEGF-inhibitors as therapy for RCC. Interestingly, point mutation of HIF1A was found in 3 of 101 clear cell RCC, two of which also had VHL mutations [18].

Recent advances in the understanding of cancer as a genetic disease have allowed the identification of clonal genetic and epigenetic alterations, which accumulate during cancer progression, often in a general temporal order. However, relatively little is known about the secondary and later genetic alterations which drive progression after the initiating event of inactivation of VHL in clear cell RCC. Even less is known about the alterations that underlie the initiation and progression of sporadic papillary or chromophobe RCC, or the importance of different tumor suppressor and signaling pathways in renal cancer. It remains that much of what we know of the molecular basis of sporadic RCC arose from identification of the genes predisposing to inherited RCC [22].

Few proto-oncogenes have been unambiguously identified as mutated in renal tumorigenesis. An examination of sequence from regions of 17 oncogenes in 83 clear cell RCC identified only 1 HRAS mutation and 1 BRAF mutation. No point mutations of EGFR, HER2/neu or PIK3CA were found [23]. This finding was confirmed in a recent systematic sequencing study of another 101 clear cell RCC [18]. Several proto-oncogenes do show amplification (mostly low-level) and/or expression level changes in primary RCC. A genome-wide single nucleotide polymorphism (SNP) array-based copy number analysis found $12 \%$ of clear cell RCC to have amplification around MYC at chromosome 8q and $30 \%$ around chromosome 7q22 an area that excludes EGFR (7p11-p12) as an amplification target [24]. An earlier study also reported no copy number amplification of EGFR [25] however the same group have reported over-expression of EGFR [26]. The HER2/neu protooncogene does not show copy number amplification [27, 28]. The most frequent area of amplification is on chromosome 5q seen in $69 \%$ of clear cell RCC [24] but the target protooncogene is unknown.

Loss of genetic material indicating inactivation of tumor suppressor genes is common in renal cancer. Several chromosomal arms or regions have been observed to be lost in primary RCC by cytogenetic [29], allelotype [30], comparative genome hybridization (CGH) [31], and SNP array studies [24]. After deletion of 3p, the most common chromosomes with LOH are $14,8,9$, and 6 deleted in $20-40 \%$ of RCC with less frequent deletion of chromosome 1 , 4, 10q, 13q, 17p and 18q. Six of the target tumor suppressor genes have been identified. These are VHL on chromosome $3 p, p 53$ on $17 \mathrm{p}, \mathrm{Rb}$ on $13 \mathrm{q}, \mathrm{p} 16^{\mathrm{INK} 4 \mathrm{a}} / \mathrm{p} 14^{\mathrm{ARF}}$ on $9 \mathrm{p}$ and PTEN on 10q. Point mutations of p53 or RB are rare [18]. Homozygous deletion accounts for the vast majority of $\mathrm{p} 16^{\mathrm{INK} 4 \mathrm{a}} / \mathrm{p} 14^{\mathrm{ARF}}$ inactivation [32]. RCC is found in patients with Cowden's Syndrome [33] caused by point mutation of PTEN. Point mutations of PTEN are rare in RCC and homozygous deletions account for most cases of biallelic inactivation [34]. PTEN does not appear to be hypermethylated in human cancer [34] although a pseudogene with sequence homology on chromosome 9 can be methylated [35] complicating analysis.

With the exception of VHL, all these tumor suppressor genes appear to be inactivated in a minority of RCC, Indeed the number with clear evidence of inactivation of the retained allele by point mutation, homozygous deletion or hypermethylation is substantially less than the number with LOH. This may simply be due to not looking hard enough. The case of 
germline mutation of VHL is instructive because as investigators searched deeper for the second mutation, more were found [36]. The target suppressor gene(s) on several of the more frequently deleted chromosomal arms e.g. 6q, 8p or 14q in RCC have not yet been identified. Subtyping of RCC by tumor suppressor inactivation may prove important for prognostic stratification.

A recent systematic sequencing of 3544 genes in 101 clear cell RCC found novel mutation of a number of genes. Four genes involved in histone modification SETD2, JARID1C, UTX and MLL2 were mutated in 12-17\% of clear cell RCC. The same study reported $10 \%$ mutation of the p600 retinoblastoma associated protein ZUBR1 gene, 7\% of the NF2 gene, and 2-3\% mutation of the WRN and NBN DNA double strand repair genes [18].

It is possible that, in addition to VHL inactivation, the same molecular genetic alterations underlie both sporadic and familial forms of clear cell RCC. Inherited VHL RCC show similar $\mathrm{LOH}$ of chromosomes 6, 8, 9 and 14 possibly at a slightly lower frequency than in sporadic clear cell RCC [37]. This may be due to the smaller size, and by implication earlier stage of development, of inherited RCC at presentation.

Advances in microarray technology led to global gene expression profiling of RCC. Early studies produced lists of genes with differential expression levels between RCC of known (good or poor) outcome [38-40], and between the three most common RCC histologic subtypes [41-43]. Gene expression also separated chromophobe RCC from oncocytoma [44] and characterized molecular classes within papillary RCC [45]. Expression array studies have also been used to discover novel VHL target genes in cell lines [46, 47] and identify molecular pathways deregulated in RCC [48]. Differences in tumor sets, array platforms, analysis of data sets and the extent of validation, typically immunohistochemical analysis of several genes, should be noted. Table 1 shows the molecular alterations that, at present, best characterize the three most common cell types.

A search for a tumor-initiating stem cell population in RCC reported that the mesenchymal stem cell marker CD105 positive cells and clones derived from RCC were enriched in tumor-initiating cells with stem characteristics [49].

\section{Epigenetics of RCC}

The best-studied epigenetic alteration in RCC is aberrant hypermethylation of normally unmethylated promoter regions of genes that are associated with transcriptional silencing. The methylation status of individual genes has been examined in normal and renal tumor cells and, more recently, global profiles of gene methylation of RCC have been studied [50]. Several classical tumor suppressor genes can be inactivated by hypermethylation as an alternative mechanism of silencing including VHL that is hypermethylated in 10-15\% of clear cell RCC [51]. There is no clear evidence of hypermethylation of FH [19] or BHD [52, 53]. The $\mathrm{p} 16$ and $\mathrm{p} 14$ suppressor genes, which have different promoter $\mathrm{CpG}$ islands are rarely methylated in RCC [19]. E-cadherin is hypermethylated but displays a variable extent of individual CpG site methylation [19]. Some classical TSG have not been found to show promoter hypermethylation in any type of human cancer such as p53 and PTEN, or Rb other than in retinoblastoma. Overall, around 30 genes including the most commonly hypermethylated gene to date RASSF1A and several genes in the Wnt signaling pathway i.e. APC, SFRPs and DKK2 have been reported to be aberrantly hypermethylated in RCC [5456]. Gene hypermethylation is present in RCC of all cell types, grade, stage, sex, age and ethnicity. A list of genes hypermethylated in RCC is reviewed in Hoffman and Cairns 2010 [57] 
As yet, there are no published studies of histone modifications in RCC but as noted above, mutations in several histone modification genes have been identified [18]. Several studies of miRNA exist however most are of relatively small numbers of RCC and differences may be due to the array platform or the methods of data analysis. More than one independent study has reported downregulation of miR-141 and miR-200c [58,59] and upregulation of miR-210 [58,60] in clear cell RCC compared to normal renal parenchymal tissue.

\section{Papillary RCC}

The MET proto-oncogene is a cell surface receptor tyrosine kinase for the ligand hepatocyte growth factor, both of which are located on human chromosome 7 . The finding of germline activating missense point mutations in the tyrosine kinase domain identified MET as a predisposition gene for hereditary papillary renal cancer [61]. In the small number of hereditary cases studied, trisomy 7 was present in the tumors and the mutant MET allele was duplicated and overexpressed [62,63]. MET appears to be less frequently mutated than VHL in sporadic RCC. In one study, missense point mutation of MET was found in 17/129 (13\%) sporadic papillary RCCs however in 8 of the 17 cases, even though there was no family history, mutation was present in the germline suggesting de novo mutation [64]. Another study found MET point mutations in only 3/60 (5\%) sporadic papillary RCCs [63]. Most papillary RCC show trisomy 7 without mutation of MET. The over-expression of MET and its ligand may confer a growth advantage [64] but is unlikely to be as oncogenic as activating point mutations. Papillary RCC has been divided into Type I and II by morphology [65] and into 3 groups by genetic alteration [66]. Type I is less common, usually of lower grade and stage, with longer survival and are associated with MET point mutations. Type II is more frequent, usually of higher nuclear grade and does not have a point mutation of MET [65, 67, 68]. MET mutations have not been reported in any other RCC type. A second gene, the fumarate hydratase $(\mathrm{FH})$ tumor suppressor gene which is a Krebs cycle enzyme, confers a rare hereditary predisposition to more aggressive papillary RCCs of type II [69]. The FH gene appears to be rarely, if ever, mutated in sporadic papillary RCC $[19,70]$.

The most common genetic events associated with papillary RCC are trisomy of chromosomes 7 and 17 and loss of the Y chromosome [71]. This pattern of genetic anomalies in papillary carcinoma is distinctly different from that of clear cell RCC, and may be used to distinguish the two, especially when morphologic features overlap [72]. We and others have noted chromosome 9p LOH in papillary RCC [73, 74]. LOH of chromosomes 6 , 8 , and 14 also have been noted in papillary RCC $[66,72,74]$. Interestingly, these are the same chromosomes that show most frequent LOH (other than 3p) in clear cell RCC [72]. LOH in papillary RCC may be more frequent than described so far since state of the art analysis of copy number, i.e by genome-wide SNP array, has not yet been performed and LOH can be underestimated by traditional cytogenetic analysis and earlier CGH technology.

\section{Chromophobe RCC}

By comparative $\mathrm{CGH}$, chromophobe carcinomas were found to be characterized by frequent (75-100\%) monosomy of multiple chromosomes, particularly 1,2, 6, 10,13,17, and 21, and consequently a lower than diploid cell copy number [75]. This finding was confirmed by microsatellite analysis of copy number and, in addition, deletion of $3 p, 8 p$ and $9 p$ was noted in up to $25 \%$ of chromophobe RCC [76]. Since only a marker on the p arm was used it is not clear if the deletions were monosomies or not and chromosome 14 was not analysed [76]. Mutation of VHL has not been found in chromophobe RCC [77]. However, point mutation of p53 is significantly more frequent at a reported $30 \%$ by sequence analysis of exons 5-8 [78] and 24\% in another study [53]. Two separate gene expression array studies reported 
upregulation of the KIT proto-oncogene in chromophobe RCC [41, 79]. Sequencing did not reveal any activating point mutations of KIT [80].

Inherited mutation of the Birt-Hogg-Dube (BHD) suppressor gene that codes for the protein folliculin predisposes to RCC in around half of families with BHD syndrome [81]. The

RCCs are most commonly hybrid oncocytic with microscopic features of both chromophobe carcinoma and oncocytoma (67\%) or chromophobe RCC (23\%). Other renal tumors including clear cell RCC occasionally are seen [82]. Mutation of folliculin appears to be absent or rare in sporadic chromophobe RCC [52, 53, 83, 84].

\section{Collecting Duct and Other Rare Forms of RCC}

Collecting duct RCC is a rare but highly aggressive tumor of the distal nephron (renal medulla) that shows LOH of chromosome 1q, 6p, 8p, 13q and 21q [85]. Mapping of chromosome 1q [86], 8p and 13q [87] have narrowed down the region but not yet identified the target suppressor genes. Renal medullary carcinoma described in African-Americans and associated with sickle cell "trait", mucinous tubulocystic RCC and other rare forms of RCC have been reviewed in Srigley and Delahunt 2009 [88].

\section{The Natural History of RCC \\ Precursor Lesions}

In the context of the natural history of the disease, it is important to consider that at some point during their development all tumors are small [89]. Renal tumors under a certain size have, historically, been referred to as renal adenomas particularly when discovered incidentally. The finding of small renal tumors in adult autopsy series suggested that the incidence of smaller RCC is much more common than "overtly malignant RCC" [90]. The definition of adenoma has changed over time and between cell types. For papillary RCC, lesions under $2.5-3 \mathrm{~cm}$ were previously termed adenoma but now adenoma is defined as $0.5 \mathrm{~cm}$ or smaller. An adenoma to carcinoma sequence has been described in papillary RCC [90]. Renal adenoma cannot be distinguished from carcinoma by morphological criteria. The distinction between adenoma and carcinoma appears somewhat arbitrary based on size and outcome and has been, and likely, will continue to be redefined. At least on a molecular genetic basis, it would seem that the precursor of a RCC is a smaller RCC sometimes called adenoma.

Premalignant precursor lesions of RCC are not well-characterized. The best described putative precursor lesions are the simple cyst to atypical cyst to clear cell RCC common in inherited VHL patients [91]. Intratubular epithelial dysplasia defined by morphological criteria of nuclear crowding and nuclear enlargement has been reported by several groups in around a quarter of RCC patients (reviewed in [90]). The dysplasia can be subdivided by the severity of the lesion from mild dysplasia to high grade renal intratubular neoplasia (RIN). However, such dysplasia remains understudied and outside the current recommendations for the pathological reporting of RCC [90].

\section{Multifocal RCC}

Approximately $10-15 \%$ of sporadic RCC are multifocal in the same kidney at presentation. Papillary RCC is more frequently multifocal than clear cell. Importantly, in many cases there is an obvious difference in size between the multiple RCC. Most commonly, there is an obvious renal carcinoma and a much smaller lesion(s) often termed satellite lesions. This designation implies that the small lesions have arisen by intra-renal spread from the main (by size) tumor. 
Two studies of a comparison of molecular genetic alterations of multifocal clear cell RCC had similar findings that suggested a common clonal origin in the majority [92, 93]. In contrast, another study found evidence for a polyclonal origin in around half of the multifocal RCC patients studied [94]. A study of multifocal papillary RCC found different alterations in each lesion from the same patient for an opposite conclusion for this cell type [95]. In addition, the accuracy of the microsatellite allelotyping in one of the studies [92] has been challenged [96], the robustness of the X-chromosome inactivation clonality assay, in general, has been questioned [97], and that an identical pattern of X-chromosome inactivation or LOH can plausibly arise by chance.

As well as insight into the natural history of RCC, multifocal RCC have been studied with regard to the implications of the presence of small lesions in the kidney remnant after nepron sparing surgery [98]. Initial observations described a lower level of recurrence after partial nephrectomy (1\%) compared to the incidence of multifocal disease (10-15\%) and implied a lesser malignancy of satellite lesions [90]. While it may be too early in the adoption of nephron sparing surgery for any increase in recurrence rate to be apparent, for T1 RCC survival after partial nephrectomy appears statistically indistinguishable from radical nephrectomy [99].

Overall, the typically smaller size of the satellite lesion(s), the physical proximity to the main tumor, the similar histopathology, and the albeit understudied similar (in clear cell) molecular alterations, all argue for the smaller lesion(s) having arisen from intra-renal spread from the main tumor. However, as discussed above, the molecular evidence remains equivocal and it is difficult to reconcile the satellite lesions having the same alterations present in the main tumor and intra-renal metastasis with the partial nephrectomy survival data.

There are RCC patients with two or more tumors of several $\mathrm{cm}$ in size in the same kidney as well as patients with bilateral RCC [100]. RCC patients younger than 40 years are at greatly increased risk of RCC in the other kidney [101]. Some of the bilateral RCC patients may be unidentified familial RCC [102].

\section{RCC in End Stage Renal Disease Patients}

In addition to individuals with inherited syndromes that strongly predispose to RCC, there is a second, rapidly increasing, group at high risk. These are are individuals on long-term dialysis particularly those with acquired cystic kidney disease (ACKD). More than 100,000 people in the US will begin treatment for end stage renal disease (ESRD) this year (www.cdc.gov). ACKD is characterized by the development of numerous fluid-filled cysts in the kidneys in individuals who have no history of hereditary cystic disease. The definition is somewhat arbitrary as the threshold of cystic changes has not been agreed upon. Thus the prevalence of ACKD in patients with end stage renal failure varies between $30 \%$ and $90 \%$ according to the definition of ACKD, time on dialysis and type of investigation performed [103]. The exact cause of this disease is not known. It occurs exclusively in patients on dialysis. The severity of disease is directly related to the duration of therapy. ACKD occurs in about $20 \%$ of patients with end stage renal disease prior to dialysis, this increases to 60$80 \%$ in patients with 4 years of dialysis, and to $90 \%$ in patients with 8 years or more of dialysis [104]. Typically, ACKD is asymptomatic in patients with acquired cystic disease who are more likely to develop RCC at an estimated 40-fold higher incidence. Renal cell carcinoma occurs approximately 20 years earlier in people with acquired renal cystic disease than in the general population. ACKD is more frequent in men and African-Americans are significantly more likely both to both be on dialysis and to have ACKD. ACKD patients have more bilateral, multifocal, and papillary RCC than the general population [103]. 
The benefit of early detection of RCC in ESRD would be that the RCC would be less likely metastatic and hence ultimately fatal. ESRD patients are not routinely scanned for RCC unless there are other issues. Transplantation also carries an increased risk for kidney cancer (RCC and TCC); this is estimated to be 15 -fold over the first three years following transplantation, and this risk increases with extent of exposure to immunosuppressive agents [105]. The prevalence of RCC in native kidneys after transplantation is around 5\% overall but $19 \%$ in ACKD patients or 54\% in patients with complex cysts [103]. The life expectancy of a transplant recipient has improved and cancer may soon be the leading cause of death late after transplantation. A marker of aggressiveness of RCC developing after transplantation could also aid in establishing priority for transplantation.

\section{Risk, Prevention, and Early Detection of RCC}

Individuals with inherited syndromes that predispose to RCC and long-term dialysis patients are at high risk but account for a minority of RCC cases. Algorithms of relative risk of RCC according to smoking status, body mass index and blood pressure have been investigated [106] and a decrease in risk was observed for men who had stopped smoking for 30 years or more [107]. The only evidence for the potential of chemoprevention for RCC are studies which show diets rich in fruit and vegetables as well as high vitamin D levels to be preventive [108]. Candidates for a future chemopreventive strategy would be inherited RCC, ESRD patients and also RCC patients at high risk of recurrence.

In regard to early detection, despite increasing incidental detection, the problem remains of the RCCs that are locally advanced or metastatic upon diagnosis. Unless risk factors are uncovered, the death rate from advanced RCCs at presentation may only be reduced by a screening test for RCC in the general population that could detect such RCC at an earlier and curative stage. Renal cancer is "neither a common nor a rare disease" [109]. However, the relative incidence of RCC and considerations of cost effectiveness virtually dictate that a screening test of the general population for RCC must be "bundled" with simultaneous screening for a, or more likely several, more common types of solid tumors; however, a screening test in non-invasive body fluids, urine or blood, will require a method of differential diagnosis of the organ site of cancer from which the positive test originated.

Molecular early detection strategies must be designed with careful regard to the abundance of tumor cells in the clinical specimen as well as the frequency and timing of the alteration to be detected [110]. $\mathrm{LOH}$ of $3 p$ and point mutation of VHL are frequent and early in clear cell RCC but urine or blood contain a low ratio of DNA from renal tumor cells to DNA from normal cells that is insufficient for the robust detection of these alterations by polymorphic marker and sequencing analysis respectively. Because point mutations occur throughout the VHL gene, rather than at hotspots of particular codons like RAS, the design of more sensitive oligonucleotide molecular tests is very complicated. However, if a tumor cell-rich biopsy specimen is available, $\mathrm{LOH}$ and point mutation can be assessed as prognostic markers.

Because aberrant hypermethylation of particular tumor suppressor and other cancer genes can be common, early and cancer specific as well as amenable to detection by the sensitive MSP technique which is capable of detecting one methylated allele from a neoplastic cell in a background of several thousand unmethylated alleles from normal cells, a number of feasibility studies of methylation-based detection of cancer in body fluids have been performed [111]. We have demonstrated the feasibility of methylation-based detection of kidney cancer. Our initial study selected a panel of 6 genes (the tumor suppressor genes VHL, p16, p14ARF and APC and the putative suppressor genes RASSF1A and Timp-3) the promoter regions of which are generally unmethylated in normal renal tissue. Using methylation specific PCR (MSP), a pattern of gene hypermethylation identical to that found 
in the RCC tissue sample was detected in matched DNA extracted from pre-operative urine samples in 44 of $50(88 \%)$ patients. Gene methylation was positively detected in urine samples from patients with organ-confined (stage I and II) RCC, including tumors as small as $2.2 \mathrm{~cm}$ in size. In contrast, methylation of all 6 genes used in the panel was absent in normal renal tissue and urine from a small number of normal and non-neoplastic disease controls [112]. We have demonstrated the feasibility of sensitive and specific detection of genes aberrantly methylated in RCC in pre-operative urine DNA [112]. Other investigators confirmed these findings in a subsequent qMSP study of gene methylation in urine DNA from patients with RCC [113]. Urakami et al reported conventional MSP-based detection of methylation of SFRP1 and other Wnt-antagonist genes in 33\% of serum of RCC patients and $0 \%$ in serum from normal age-matched controls [56]. This approach requires validation in larger, well-defined populations with optimized and standardized methodology. Further insight into the timing of gene methylation during ageing and the earliest stages of neoplastic development will be necessary. Depending upon the population and the specimen to be screened, differential diagnosis will be of a greater or lesser degree of importance.

\section{Active Surveillance}

Once diagnosed, the standard intervention for renal cell carcinoma (RCC) is surgical resection, due to the limited effectiveness of systemic medical treatments. However, with the widespread availability of non-invasive cross-sectional imaging, an increasing proportion of newly identified renal masses are small, asymptomatic and incidental, and in many individuals the benefit of treating these lesions may not outweigh the risks or possible side effects of surgical excision. Surveillance with delayed primary treatment has been proposed as a management option for selected patients with RCC to defer and possibly avoid the negative consequences of surgery [114]. Approximately $30 \%$ of lesions under surveillance do not grow. Of the other $70 \%$, by definition half grow slower than the median growth rate over 12 months of 4-5mm and the other half show faster growth than the median. At Fox Chase Cancer Center, when a lesion reaches a threshold size of $3 \mathrm{~cm}$, whether through fast or slow interval growth (based on NCI experience with RCC in inherited VHL patients [115] where kidney preservation is crucial), the patient is directed to surgery. If a lesion under $3 \mathrm{~cm}$ has shown rapid growth, the urologist usually recommends surgery and does not wait until the $3 \mathrm{~cm}$ size threshold is reached. Some of the $65 \%$ of patients with lesions of no or slower growth may, because of anxiety, opt for surgery.

A specific shortcoming of this manner of management is the inability to differentiate between aggressive or indolent tumors based upon the information available from pretreatment clinical assessments. At present there are no recognized non-pathologic markers that might separate aggressive from indolent behavior, and prognostic information regarding the long-term RCC outcome for an individual patient is based primarily upon pathologic data obtained from definitive surgical resection. Markers which can differentiate between benign and malignant small renal masses and/or predict growth rate that are amenable to detection in needle biopsy or non-invasive body fluids are needed.

\section{Tumor Behavior and Prognostic Molecular Markers}

The stage of the tumor, grade within stage, the histological cell type as well as clinical indications are used for prognosis of RCC. Identification of the molecular alterations that contribute to the variation in tumor behavior and clinical outcome within organ-confined, locally advanced, or metatstatic RCC is needed for improved management of RCC.

Molecular markers can be incorporated into nomograms for counseling of patients and for patient stratification in clinical trials [116]. The majority of studies have examined prognostic markers, e.g. carbonic anhydrase IX (CA-IX), almost exclusively by immunohistochemistry usually in the context of advanced RCC. Other markers investigated 
include p53, p21, Hif-1 $\alpha$ and Survivin reviewed by Lam et al 2008 [117]. Some global array studies have examined expression signatures of progression but in small numbers of organconfined RCC and as part of a wider analysis [38, 40]. Even so, genes previously implicated in the progression of RCC were identified e.g. elevated expression of the Caveolin-1 gene [40] previously implicated as an immunohistochemical marker for poor disease-free survival in non-metatstatic $(<\mathrm{pT} 4) \mathrm{RCC}[118]$.

The colorectal cancer model of molecular progression has become the paradigm for progression of all human solid tumors [119]. Most solid neoplasms are now thought to accumulate a series of genetic and epigenetic changes as they progress through well-defined clinical and histopathological changes. The association of particular molecular markers with progression and outcome of disease means that the status of certain markers can be used to identify its likelihood for progression. LOH of chromosomes $8 p, 9 p$ and $14 q$ have been associated with higher grade and stage in clear cell RCC and papillary RCC [74, 120]. LOH of chromosome $9 \mathrm{p}$ has been correlated with progression in locally advanced (pT3NOM0) clear cell RCC [121] and progression of papillary RCC [122].

An understudied area is prognostic molecular markers to identify patients at higher risk of recurrence after surgery for organ-confined RCC. Patients at higher risk of recurrence could be screened more often and potentially in the future could be candidates for adjuvant therapy. Patients at lower risk might be screened less often with reduction in cost and anxiety. It is not known if the alterations discussed above have prognostic value for RCC confined within the renal capsule (pT1-2).

\section{Conclusions}

Changes in the presentation and management of RCC as well as the fact that approximately $40 \%$ of RCC patients will die from their disease highlight the need for additional translational research. The inherited forms of RCC have provided insight into the initiating events and early development of the disease; however we know little about the molecular events that drive progression. Consortium-driven omics studies in large numbers of RCC specimens, such as the Cancer Genome Atlas, will likely identify many as yet unidentified point mutations and provide global genomic and epigenomic profiles of the same large tumor set. Such data should facilitate; the further elucidation of the biological basis of disease, a better understanding of disease progression, and the discovery of molecular markers for translational application to diagnosis and prognosis of early RCC.

\section{Acknowledgments}

Thanks to Robert G. Uzzo, Tahseen Al-Saleem and Gary Hudes at FCCC for helpful discussion. This publication was supported in part by grant number 3U01CA111242-05 and P30 CA006927 from the National Cancer Institute. Its contents are solely the responsibility of the authors and does not necessarily represent the official views of the National Cancer Institute or the National Institutes of Health. Additional funds were provided by Fox Chase Cancer Center via institutional support of the Kidney Cancer Keystone Program.

\section{References}

1. Jemal A, Siegel R, Ward E, Hao Y, Xu J, Thun MJ. Cancer statistics, 2009. CA Cancer J Clin. 2009; 59:225-249. [PubMed: 19474385]

2. Russo P. Contemporary understanding and management of renal cortical tumors. Urol Clin North Am. 2008; 35:xiii-xvii. [PubMed: 18992606]

3. Decastro GJ, McKiernan JM. Epidemiology, clinical staging, and presentation of renal cell carcinoma. Urol Clin North Am. 2008; 35:581-592. vi. [PubMed: 18992612] 
4. Dhote R, Pellicer-Coeuret M, Thiounn N, Debre B, Vidal-Trecan G. Risk factors for adult renal cell carcinoma: a systematic review and implications for prevention. BJU Int. 2000; 86:20-27. [PubMed: 10886077]

5. Gibbons RP, Monte JE, Correa RJ Jr, Mason JT. Manifestations of renal cell carcinoma. Urology. 1976; 8:201-206. [PubMed: 788291]

6. Cohen HT, McGovern FJ. Renal-cell carcinoma. N Engl J Med. 2005; 353:2477-2490. [PubMed: 16339096]

7. Jones PA, Vogelzang NJ, Gomez Jao. Report of the Kidney/Bladder Cancer Progress Review Group. NCI. 2002

8. Hutson TE, Figlin RA. Novel therapeutics for metastatic renal cell carcinoma. Cancer. 2009; 115:2361-2367. [PubMed: 19402059]

9. Kovacs G, Akhtar M, Beckwith BJ, et al. The Heidelberg classification of renal cell tumours. J Pathol. 1997; 183:131-133. [PubMed: 9390023]

10. American Joint Committee on Cancer. AJCC Cancer Staging Handbook. 7. Springer; 2010.

11. Hock LM, Lynch J, Balaji KC. Increasing incidence of all stages of kidney cancer in the last 2 decades in the United States: an analysis of surveillance, epidemiology and end results program data. J Urol. 2002; 167:57-60. [PubMed: 11743275]

12. Delahunt B, Bethwaite PB, Nacey JN. Outcome prediction for renal cell carcinoma: evaluation of prognostic factors for tumours divided according to histological subtype. Pathology. 2007; 39:459-465. [PubMed: 17886093]

13. Delahunt B. Advances and controversies in grading and staging of renal cell carcinoma. Mod Pathol. 2009; 22(Suppl 2):S24-36. [PubMed: 19494851]

14. Pavlovich CP, Schmidt LS. Searching for the hereditary causes of renal-cell carcinoma. Nat Rev Cancer. 2004; 4:381-393. [PubMed: 15122209]

15. Latif F, Tory K, Gnarra J, et al. Identification of the von Hippel-Lindau disease tumor suppressor gene. Science. 1993; 260:1317-1320. [PubMed: 8493574]

16. Pavlovich CP, Schmidt LS, Phillips JL. The genetic basis of renal cell carcinoma. Urol Clin North Am. 2003; 30:437-454. vii. [PubMed: 12953747]

17. Gnarra JR, Tory K, Weng Y, et al. Mutations of the $V H L$ tumour suppressor gene in renal carcinoma. Nature Genet. 1994; 7:85-90. [PubMed: 7915601]

18. Dalgliesh GL, Furge K, Greenman C, et al. Systematic sequencing of renal carcinoma reveals inactivation of histone modifying genes. Nature. 2010

19. Dulaimi E, Ibanez De Caceres I, Uzzo RG, et al. Promoter Hypermethylation Profile of Kidney Cancer. Clinical Cancer Research. 2004

20. Gordan JD, Lal P, Dondeti VR, et al. HIF-alpha effects on c-Myc distinguish two subtypes of sporadic VHL-deficient clear cell renal carcinoma. Cancer Cell. 2008; 14:435-446. [PubMed: 19061835]

21. Kaelin WG Jr. The von Hippel-Lindau tumor suppressor protein and clear cell renal carcinoma. Clin Cancer Res. 2007; 13:680s-684s. [PubMed: 17255293]

22. Linehan WM, Zbar B. Focus on kidney cancer. Cancer Cell. 2004; 6:223-228. [PubMed: 15380513]

23. Thomas RK, Baker AC, Debiasi RM, et al. High-throughput oncogene mutation profiling in human cancer. Nat Genet. 2007; 39:347-351. [PubMed: 17293865]

24. Beroukhim R, Brunet JP, Di Napoli A, et al. Patterns of gene expression and copy-number alterations in von-hippel lindau disease-associated and sporadic clear cell carcinoma of the kidney. Cancer Res. 2009; 69:4674-4681. [PubMed: 19470766]

25. Moch H, Sauter G, Gasser TC, et al. EGF-r gene copy number changes in renal cell carcinoma detected by fluorescence in situ hybridization. J Pathol. 1998; 184:424-429. [PubMed: 9664910]

26. Moch H, Sauter G, Buchholz N, et al. Epidermal growth factor receptor expression is associated with rapid tumor cell proliferation in renal cell carcinoma. Hum Pathol. 1997; 28:1255-1259. [PubMed: 9385930]

27. Schraml P, Kononen J, Bubendorf L, et al. Tissue microarrays for gene amplification surveys in many different tumor types. Clin Cancer Res. 1999; 5:1966-1975. [PubMed: 10473073] 
28. Weidner U, Peter S, Strohmeyer T, Hussnatter R, Ackermann R, Sies H. Inverse relationship of epidermal growth factor receptor and HER2/neu gene expression in human renal cell carcinoma. Cancer Res. 1990; 50:4504-4509. [PubMed: 1973362]

29. Kovacs G, Szucs S, De Riese W, Baumgartel H. Specific chromosome aberration in human renal cell carcinoma. Int J Cancer. 1987; 40:171-178. [PubMed: 3610386]

30. Thrash-Bingham CA, Greenberg RE, Howard S, et al. Comprehensive allelotyping of human renal cell carcinomas using microsatellite DNA probes. Proc Natl Acad Sci USA. 1995; 92:2854-2858. [PubMed: 7708737]

31. Wilhelm M, Veltman JA, Olshen AB, et al. Array-based comparative genomic hybridization for the differential diagnosis of renal cell cancer. Cancer Res. 2002; 62:957-960. [PubMed: $11861363]$

32. Cairns P, Polascik TJ, Eby Y, et al. Frequency of homozygous deletion at $p 16 / C D K N 2$ in primary human tumours. Nature Genet. 1995; 11:210-212. [PubMed: 7550353]

33. Haibach H, Burns TW, Carlson HE, Burman KD, Deftos LJ. Multiple hamartoma syndrome (Cowden's disease) associated with renal cell carcinoma and primary neuroendocrine carcinoma of the skin (Merkel cell carcinoma). Am J Clin Pathol. 1992; 97:705-712. [PubMed: 1575215]

34. Cairns P, Evron E, Okami K, et al. Point mutation and homozygous deletion of PTEN/MMAC1 in primary bladder cancers. Oncogene. 1998; 16:3215-3218. [PubMed: 9671402]

35. Zysman MA, Chapman WB, Bapat B. Considerations when analyzing the methylation status of PTEN tumor suppressor gene. Am J Pathol. 2002; 160:795-800. [PubMed: 11891178]

36. Stolle C, Glenn G, Zbar B, et al. Improved detection of germline mutations in the von HippelLindau disease tumor suppressor gene. Hum Mutat. 1998; 12:417-423. [PubMed: 9829911]

37. Kovacs G, Emanuel A, Neumann HP, Kung HF. Cytogenetics of renal cell carcinomas associated with von Hippel-Lindau disease. Genes Chromosomes Cancer. 1991; 3:256-262. [PubMed: 1958591]

38. Takahashi M, Rhodes DR, Furge KA, et al. Gene expression profiling of clear cell renal cell carcinoma: gene identification and prognostic classification. Proc Natl Acad Sci U S A. 2001; 98:9754-9759. [PubMed: 11493696]

39. Vasselli JR, Shih JH, Iyengar SR, et al. Predicting survival in patients with metastatic kidney cancer by gene-expression profiling in the primary tumor. Proc Natl Acad Sci U S A. 2003; 100:6958-6963. [PubMed: 12777628]

40. Jones J, Otu H, Spentzos D, et al. Gene signatures of progression and metastasis in renal cell cancer. Clin Cancer Res. 2005; 11:5730-5739. [PubMed: 16115910]

41. Higgins JP, Shinghal R, Gill H, et al. Gene expression patterns in renal cell carcinoma assessed by complementary DNA microarray. Am J Pathol. 2003; 162:925-932. [PubMed: 12598325]

42. Takahashi M, Yang XJ, Sugimura J, et al. Molecular subclassification of kidney tumors and the discovery of new diagnostic markers. Oncogene. 2003; 22:6810-6818. [PubMed: 14555994]

43. Young AN, Amin MB, Moreno CS, et al. Expression profiling of renal epithelial neoplasms: a method for tumor classification and discovery of diagnostic molecular markers. Am J Pathol. 2001; 158:1639-1651. [PubMed: 11337362]

44. Rohan S, Tu JJ, Kao J, et al. Gene expression profiling separates chromophobe renal cell carcinoma from oncocytoma and identifies vesicular transport and cell junction proteins as differentially expressed genes. Clinical Cancer Research. 2006; 12:6937-6945. [PubMed: 17145811]

45. Yang XJ, Tan MH, Kim HL, et al. A molecular classification of papillary renal cell carcinoma. Cancer Res. 2005; 65:5628-5637. [PubMed: 15994935]

46. Abdulrahman M, Maina EN, Morris MR, et al. Identification of novel VHL targets that are associated with the development of renal cell carcinoma. Oncogene. 2007; 26:1661-1672. [PubMed: 17001320]

47. Maina EN, Morris MR, Zatyka M, et al. Identification of novel VHL target genes and relationship to hypoxic response pathways. Oncogene. 2005; 24:4549-4558. [PubMed: 15824735]

48. Furge KA, Tan MH, Dykema K, et al. Identification of deregulated oncogenic pathways in renal cell carcinoma: an integrated oncogenomic approach based on gene expression profiling. Oncogene. 2007; 26:1346-1350. [PubMed: 17322920] 
49. Bussolati B, Bruno S, Grange C, Ferrando U, Camussi G. Identification of a tumor-initiating stem cell population in human renal carcinomas. FASEB J. 2008; 22:3696-3705. [PubMed: 18614581]

50. Ibanez de Caceres I, Dulaimi E, Hoffman AM, Al-Saleem T, Uzzo RG, Cairns P. Identification of novel target genes by an epigenetic reactivation screen of renal cancer. Cancer Res. 2006; 66:5021-5028. [PubMed: 16707423]

51. Herman JG, Latif F, Weng Y, et al. Silencing of the VHL tumor-suppressor gene by DNA methylation in renal carcinoma. Proc Natl Acad Sci USA. 1994; 91:9700-9704. [PubMed: 7937876]

52. da Silva NF, Gentle D, Hesson LB, Morton DG, Latif F, Maher ER. Analysis of the Birt-HoggDube (BHD) tumour suppressor gene in sporadic renal cell carcinoma and colorectal cancer. J Med Genet. 2003; 40:820-824. [PubMed: 14627671]

53. Gad S, Lefevre SH, Khoo SK, et al. Mutations in BHD and TP53 genes, but not in HNF1beta gene, in a large series of sporadic chromophobe renal cell carcinoma. Br J Cancer. 2007; 96:336-340. [PubMed: 17133269]

54. Esteller M, Sparks A, Toyota M, et al. Analysis of adenomatous polyposis coli promoter hypermethylation in human cancer. Cancer Res. 2000; 60:4366-4371. [PubMed: 10969779]

55. Dahl E, Wiesmann F, Woenckhaus M, et al. Frequent loss of SFRP1 expression in multiple human solid tumours: association with aberrant promoter methylation in renal cell carcinoma. Oncogene. 2007; 26:5680-5691. [PubMed: 17353908]

56. Urakami S, Shiina H, Enokida H, et al. Combination analysis of hypermethylated Wnt-antagonist family genes as a novel epigenetic biomarker panel for bladder cancer detection. Clin Cancer Res. 2006; 12:2109-2116. [PubMed: 16609023]

57. Hoffman A, Cairns P. Kidney and Bladder Cancer Epigenetics. Epigenomics. 2010 in press.

58. Jung M, Mollenkopf HJ, Grimm C, et al. MicroRNA profiling of clear cell renal cell cancer identifies a robust signature to define renal malignancy. J Cell Mol Med. 2009; 13:3918-3928. [PubMed: 19228262]

59. Nakada C, Matsuura K, Tsukamoto Y, et al. Genome-wide microRNA expression profiling in renal cell carcinoma: significant down-regulation of miR-141 and miR-200c. J Pathol. 2008; 216:418427. [PubMed: 18925646]

60. Juan D, Alexe G, Antes T, et al. Identification of a MicroRNA Panel for Clear-cell Kidney Cancer. Urology. 2009

61. Schmidt L, Duh FM, Chen F, et al. Germline and somatic mutations in the tyrosine kinase domain of the MET proto-oncogene in papillary renal carcinomas. Nat Genet. 1997; 16:68-73. [PubMed: 9140397]

62. Zhuang Z, Park WS, Pack S, et al. Trisomy 7-harbouring non-random duplication of the mutant MET allele in hereditary papillary renal carcinomas. Nat Genet. 1998; 20:66-69. [PubMed: 9731534]

63. Fischer J, Palmedo G, von Knobloch R, et al. Duplication and overexpression of the mutant allele of the MET proto-oncogene in multiple hereditary papillary renal cell tumours. Oncogene. 1998; 17:733-739. [PubMed: 9715275]

64. Schmidt L, Junker K, Nakaigawa N, et al. Novel mutations of the MET proto-oncogene in papillary renal carcinomas. Oncogene. 1999; 18:2343-2350. [PubMed: 10327054]

65. Delahunt B, Eble JN. Papillary renal cell carcinoma: a clinicopathologic and immunohistochemical study of 105 tumors. Mod Pathol. 1997; 10:537-544. [PubMed: 9195569]

66. Szponar A, Zubakov D, Pawlak J, Jauch A, Kovacs G. Three genetic developmental stages of papillary renal cell tumors: duplication of chromosome 1q marks fatal progression. Int J Cancer. 2009; 124:2071-2076. [PubMed: 19123481]

67. Delahunt B, Eble JN, McCredie MR, Bethwaite PB, Stewart JH, Bilous AM. Morphologic typing of papillary renal cell carcinoma: comparison of growth kinetics and patient survival in 66 cases. Hum Pathol. 2001; 32:590-595. [PubMed: 11431713]

68. Lubensky IA, Schmidt L, Zhuang Z, et al. Hereditary and sporadic papillary renal carcinomas with c-met mutations share a distinct morphological phenotype. Am J Pathol. 1999; 155:517-526. [PubMed: 10433944] 
69. Tomlinson IP, Alam NA, Rowan AJ, et al. Germline mutations in FH predispose to dominantly inherited uterine fibroids, skin leiomyomata and papillary renal cell cancer. Nat Genet. 2002; 30:406-410. [PubMed: 11865300]

70. Kiuru M, Lehtonen R, Arola J, et al. Few FH mutations in sporadic counterparts of tumor types observed in hereditary leiomyomatosis and renal cell cancer families. Cancer Res. 2002; 62:4554 4557. [PubMed: 12183404]

71. Kovacs G, Fuzesi L, Emanual A, Kung HF. Cytogenetics of papillary renal cell tumors. Genes Chromosomes Cancer. 1991; 3:249-255. [PubMed: 1958590]

72. Kovacs G. Molecular cytogenetics of renal cell tumors. Adv Cancer Res. 1993; 62:89-124. [PubMed: 8109322]

73. Cairns P, Tokino K, Eby Y, Sidransky D. Localization of tumor suppressor loci on chromosome 9 in primary human renal cell carcinomas. Cancer Res. 1995; 55:224-227. [PubMed: 7812948]

74. Schullerus D, Herbers J, Chudek J, Kanamaru H, Kovacs G. Loss of heterozygosity at chromosomes $8 \mathrm{p}, 9 \mathrm{p}$, and $14 \mathrm{q}$ is associated with stage and grade of non-papillary renal cell carcinomas. J Pathol. 1997; 183:151-155. [PubMed: 9390026]

75. Speicher MR, Schoell B, du Manoir S, et al. Specific loss of chromosomes 1, 2, 6, 10, 13, 17, and 21 in chromophobe renal cell carcinomas revealed by comparative genomic hybridization. Am $\mathrm{J}$ Pathol. 1994; 145:356-364. [PubMed: 7519827]

76. Bugert P, Kovacs G. Molecular differential diagnosis of renal cell carcinomas by microsatellite analysis. Am J Pathol. 1996; 149:2081-2088. [PubMed: 8952540]

77. Kenck C, Wilhelm M, Bugert P, Staehler G, Kovacs G. Mutation of the VHL gene is associated exclusively with the development of non-papillary renal cell carcinomas. J Pathol. 1996; 179:157161. [PubMed: 8758207]

78. Contractor H, Zariwala M, Bugert P, Zeisler J, Kovacs G. Mutation of the p53 tumour suppressor gene occurs preferentially in the chromophobe type of renal cell tumour. J Pathol. 1997; 181:136139. [PubMed: 9120715]

79. Yamazaki K, Sakamoto M, Ohta T, Kanai Y, Ohki M, Hirohashi S. Overexpression of KIT in chromophobe renal cell carcinoma. Oncogene. 2003; 22:847-852. [PubMed: 12584564]

80. Haitel A, Susani M, Wick N, Mazal PR, Wrba F. c-kit overexpression in chromophobe renal cell carcinoma is not associated with c-kit mutation of exons 9 and 11. Am J Surg Pathol. 2005; 29:842. [PubMed: 15897759]

81. Toro JR, Wei MH, Glenn GM, et al. BHD mutations, clinical and molecular genetic investigations of Birt-Hogg-Dube syndrome: a new series of 50 families and a review of published reports. $\mathrm{J}$ Med Genet. 2008; 45:321-331. [PubMed: 18234728]

82. Nickerson ML, Warren MB, Toro JR, et al. Mutations in a novel gene lead to kidney tumors, lung wall defects, and benign tumors of the hair follicle in patients with the Birt-Hogg-Dube syndrome. Cancer Cell. 2002; 2:157-164. [PubMed: 12204536]

83. Khoo SK, Kahnoski K, Sugimura J, et al. Inactivation of BHD in sporadic renal tumors. Cancer Res. 2003; 63:4583-4587. [PubMed: 12907635]

84. Nagy A, Zoubakov D, Stupar Z, Kovacs G. Lack of mutation of the folliculin gene in sporadic chromophobe renal cell carcinoma and renal oncocytoma. Int J Cancer. 2004; 109:472-475. [PubMed: 14961590]

85. Polascik TJ, Cairns P, Epstein JI, et al. Distal nephron renal tumors: microsatellite allelotype. Cancer Res. 1996; 56:1892-1895. [PubMed: 8620510]

86. Steiner G, Cairns P, Polascik TJ, et al. High-density mapping of chromosomal arm 1q in renal collecting duct carcinoma: region of minimal deletion at 1q32.1-32.2. Cancer Res. 1996; 56:50445046. [PubMed: 8895762]

87. Schoenberg M, Cairns P, Brooks JD, et al. Frequent loss of chromosome arms 8p and 13q in collecting duct carcinoma (CDC) of the kidney. Genes Chromosomes Cancer. 1995; 12:76-80. [PubMed: 7534117]

88. Srigley JR, Delahunt B. Uncommon and recently described renal carcinomas. Mod Pathol. 2009; 22(Suppl 2):S2-S23. [PubMed: 19494850] 
89. Presti J, Moch JCH, Gelb AB, Huynh D, Waldman FM. Initiating genetic events in small renal neoplasms detected by comparative genomic hybridization. J Urol. 1998; 160:1557-1561. [PubMed: 9751412]

90. Van Poppel H, Nilsson S, Algaba F, et al. Precancerous lesions in the kidney. Scand J Urol Nephrol Suppl. 2000:136-165. [PubMed: 11144893]

91. Lubensky IA, Gnarra JR, Bertheau P, Walther MM, Linehan WM, Zhuang Z. Allelic deletions of the VHL gene detected in multiple microscopic clear cell renal lesions in von Hippel-Lindau disease patients. Am J Pathol. 1996; 149:2089-2094. [PubMed: 8952541]

92. Junker K, Thrum K, Schlichter A, Muller G, Hindermann W, Schubert J. Clonal origin of multifocal renal cell carcinoma as determined by microsatellite analysis. J Urol. 2002; 168:26322636. [PubMed: 12441999]

93. Miyake H, Nakamura H, Hara I, et al. Multifocal renal cell carcinoma: evidence for a common clonal origin. Clin Cancer Res. 1998; 4:2491-2494. [PubMed: 9796982]

94. Cheng L, MacLennan GT, Zhang S, et al. Evidence for polyclonal origin of multifocal clear cell renal cell carcinoma. Clin Cancer Res. 2008; 14:8087-8093. [PubMed: 19088024]

95. Jones TD, Eble JN, Wang M, et al. Molecular genetic evidence for the independent origin of multifocal papillary tumors in patients with papillary renal cell carcinomas. Clin Cancer Res. 2005; 11:7226-7233. [PubMed: 16243792]

96. Kovacs G. Re: clonal origin of multifocal renal cell carcinoma as determined by microsatellite analysis. J Urol. 2003; 170:1325-1326. author reply 1326. [PubMed: 14501758]

97. Jang SJ, Mao L. Methylation patterns in human androgen receptor gene and clonality analysis. Cancer Res. 2000; 60:864-866. [PubMed: 10706095]

98. Gohji K, Hara I, Gotoh A, et al. Multifocal renal cell carcinoma in Japanese patients with tumors with maximal diameters of $50 \mathrm{~mm}$. or less. J Urol. 1998; 159:1144-1147. [PubMed: 9507818]

99. Campbell SC, Novick AC, Belldegrun A, et al. Guideline for management of the clinical T1 renal mass. J Urol. 2009; 182:1271-1279. [PubMed: 19683266]

100. Reuter VE, Presti JC Jr. Contemporary approach to the classification of renal epithelial tumors. Semin Oncol. 2000; 27:124-137. [PubMed: 10768592]

101. Wiklund F, Tretli S, Choueiri TK, Signoretti S, Fall K, Adami HO. Risk of bilateral renal cell cancer. J Clin Oncol. 2009; 27:3737-3741. [PubMed: 19597028]

102. Linehan WM. Genetic basis of bilateral renal cancer: implications for evaluation and management. J Clin Oncol. 2009; 27:3731-3733. [PubMed: 19597019]

103. Schwarz A, Vatandaslar S, Merkel S, Haller H. Renal cell carcinoma in transplant recipients with acquired cystic kidney disease. Clin J Am Soc Nephrol. 2007; 2:750-756. [PubMed: 17699492]

104. Fick-Brosnahan, GM. Polycystic and acquired cystic kidney disease. In: Greenberg, A., editor. Primer on Kidney Diseases. San Francisco: Academic Press; 2001. p. 303-308.

105. Scandling JD. Acquired cystic kidney disease and renal cell cancer after transplantation: time to rethink screening? Clin J Am Soc Nephrol. 2007; 2:621-622. [PubMed: 17699473]

106. Chow WH, Gridley G, Fraumeni JF Jr, Jarvholm B. Obesity, hypertension, and the risk of kidney cancer in men. N Engl J Med. 2000; 343:1305-1311. [PubMed: 11058675]

107. Parker AS, Cerhan JR, Janney CA, Lynch CF, Cantor KP. Smoking cessation and renal cell carcinoma. Ann Epidemiol. 2003; 13:245-251. [PubMed: 12684190]

108. Karami S, Brennan P, Navratilova M, et al. Vitamin d pathway genes, diet, and risk of renal cell carcinoma. Int J Endocrinol. 2010:879362. [PubMed: 20049159]

109. Bast RC Jr, Brewer M, Zou C, et al. Prevention and early detection of ovarian cancer: mission impossible? Recent Results Cancer Res. 2007; 174:91-100. [PubMed: 17302189]

110. Cairns P, Sidransky D. Molecular methods for the diagnosis of cancer. Biochim Biophys Acta. 1999; 1423:C11-C18. [PubMed: 10214347]

111. Cairns P. Gene methylation and early detection of genitourinary cancer: the road ahead. Nat Rev Cancer. 2007; 7:531-543. [PubMed: 17585333]

112. Battagli C, Uzzo RG, Dulaimi E, et al. Promoter Hypermethylation of Tumor Suppressor Genes in Urine from Kidney Cancer Patients. Cancer Res. 2003; 63:8695-8699. [PubMed: 14695183] 
113. Hoque MO, Begum S, Topaloglu O, et al. Quantitative detection of promoter hypermethylation of multiple genes in the tumor, urine, and serum DNA of patients with renal cancer. Cancer Res. 2004; 64:5511-5517. [PubMed: 15289362]

114. Chawla SN, Crispen PL, Hanlon AL, Greenberg RE, Chen DY, Uzzo RG. The natural history of observed enhancing renal masses: meta-analysis and review of the world literature. J Urol. 2006; 175:425-431. [PubMed: 16406965]

115. Duffey BG, Choyke PL, Glenn G, et al. The relationship between renal tumor size and metastases in patients with von Hippel-Lindau disease. J Urol. 2004; 172:63-65. [PubMed: 15201738]

116. Kontak JA, Campbell SC. Prognostic factors in renal cell carcinoma. Urol Clin North Am. 2003; 30:467-480. [PubMed: 12953749]

117. Lam JS, Klatte T, Kim HL, et al. Prognostic factors and selection for clinical studies of patients with kidney cancer. Crit Rev Oncol Hematol. 2008; 65:235-262. [PubMed: 17931881]

118. Campbell L, Gumbleton M, Griffiths DF. Caveolin-1 overexpression predicts poor disease-free survival of patients with clinically confined renal cell carcinoma. Br J Cancer. 2003; 89:19091913. [PubMed: 14612902]

119. Fearon ER, Vogelstein B. A genetic model for colorectal tumorigenesis. Cell. 1990; 61:759-767. [PubMed: 2188735]

120. Béroud C, Fournet J-C, Jeanpierre C, et al. Correlations of allelic imbalance of chromosome 14 with adverse prognostic parameters in 148 renal cell carcinomas. Genes Chromosomes Cancer. 1996; 17:215-224. [PubMed: 8946203]

121. Moch H, Presti JC Jr, Sauter G, et al. Genetic aberrations detected by comparative genomic hybridization are associated with clinical outcome in renal cell carcinoma. Cancer Res. 1996; 56:27-30. [PubMed: 8548768]

122. Schraml P, Muller D, Bednar R, et al. Allelic loss at the D9S171 locus on chromosome 9p13 is associated with progression of papillary renal cell carcinoma. J Pathol. 2000; 190:457-461. [PubMed: 10699995] 


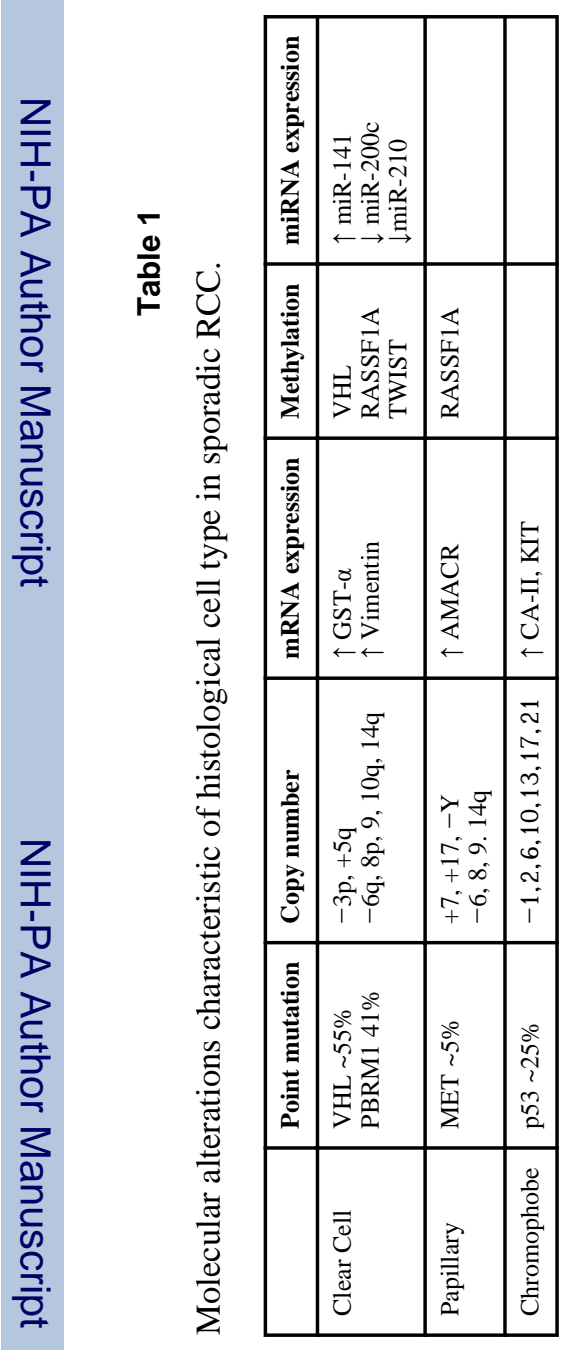

Cancer Biomark. Author manuscript; available in PMC 2012 March 20. 